\title{
Optimum Design of Outrigger and Belt Truss Systems Using Genetic Algorithm
}

\author{
Radu Hulea, Bianca Parv, Monica Nicoreac and Bogdan Petrina \\ Department of Structural Mechanics, Faculty of Civil Engineering, Technical University of Cluj-Napoca, Cluj-Napoca 400020, \\ Romania
}

\begin{abstract}
There are many structural lateral systems used in tall buildings: rigid frames, braced frames, shear walls, tubular structures and core structures. The outrigger and belt truss systems are efficient structures for drift control and base moment reduction in tall buildings where the core alone is not rigid enough to resist lateral loads. Perimeter columns are mobilized for increasing the effective width of the structure, and they developed tension in the windward columns and compression in the leeward columns. Optimum locations for the outriggers have been studied because of the influence on the top displacement and base moment in the core. It was analyzed the optimal position for two to seven outriggers and belt trusses, aiming to achieve minimum bending moment and minimum drift.
\end{abstract}

Key words: Outrigger system, optimum location, genetic algorithm.

\section{Introduction}

The history of tall buildings can be traced back to 19th century, in the United States of America, where most of them where built. Nowadays the trend of building high-rise structures can be associated with countries like China, United Arab Emirates, Malaysia or Singapore. As high-rise buildings are stretching towards the sky, problems with top deflection and base moment in the core can govern the choice and design of the structural system. Outrigger and belt truss structures represent a very efficient structural system because of the outriggers that reduce the top deflection and the moment at the core base. This is confirmed by the numerous core supported tall buildings that incorporate outriggers.

Approximate methods were proposed by several authors: Taranath [1] studied the optimum location of a single outrigger and two outriggers respectively, by

Corresponding author: Radu Hulea, Ph.D., research fields: awnings optimization for medium and large stadium, tall buildings optimization having the lateral load resisting systems which include central core, shear walls or outrigger and belt truss systems, optimization using heuristic optimization. E-mail: radu.hulea@gmail.ro. replacing the outriggers, considered to be infinitely rigid, with a restraining spring; Smith and Coull [2] chose a compatibility method where the rotation of the core at outrigger level is equal to the outrigger rotation. The structure was considered to have uniform core, columns and outriggers throughout the height. The optimum location was found by maximizing the top deflection reduction and a non-dimensional characteristic parameter $\omega$ was introduced in order to study the performance of this type of structures; $\mathrm{Wu}$ and $\mathrm{Li}$ [3] studied the performance of structures with multiple outriggers subjected to horizontal loads, uniformly or triangularly distributed. The influence of outrigger positions and stiffness of core, columns and outriggers on the fundamental vibration period of the structure was also analysed; Hoenderkamp and Bakker [4] proposed a graphical preliminary analysis method for structures with braced frames core and outriggers.

Compared to the method proposed by Smith and Coull [2], which includes the bending stiffness of the core and outriggers and the axial rigidity of the columns, Hoenderkamp and Bakker's method [4] has the advantage of comprising two more values of 
stiffness: racking shear stiffness of the braced frame and outriggers. Lee and Kim [5] conceptualized the outrigger-braced structure as a cantilever beam with rotational springs and took into consideration the shear rigidity of the core and outrigger. A two dimensional frame model was also developed by him, where each member of the structural system (core, outriggers and columns) were modeled as beam elements with shear rigidity considered.

A problem with outriggers having too much stiffness is mentioned by Wu and $\mathrm{Li}$ [3], who draw attention on the issue of weak floors near this outrigger levels. The reduction of base moment is maximized while keeping the top drift under a required limit. Wu and $\mathrm{Li}$ [3] solve this problem of optimum design with constraints, with the help of a computer program developed in Matlab. This paper presents an optimum design problem similar to the one reported above, but solved using genetic algorithm.

\section{Review of Analytical Approach}

Smith and Coull [2] started their analysis by considering a two-outrigger structure, for which they wrote the two compatibility equations, written for each outrigger floor: the rotation of the core, at outrigger level, is equal to the outrigger rotation. The simplified form of the two equations is given as follows [2]:

$$
\begin{aligned}
& M_{1}\left[S_{v}+S_{h}\left(H-x_{1}\right)\right]+M_{2} S_{h}\left(H-x_{1}\right) \\
& =w / 6 E I\left(H^{3}-x_{1}^{3}\right) \\
& M_{1} S_{h}\left(H-\mathrm{x}_{2}\right)+M_{2}\left[S_{v}+S_{h}\left(H-x_{1}\right)\right] \\
& ={ }^{w} / 6 E I\left(H^{3}-x_{1}^{3}\right)
\end{aligned}
$$

where, $S_{h}$ and $S_{v}$ are:

$$
\begin{gathered}
S_{h}=1 / E I_{t}+1 / E I_{c} \\
S_{v}=d / 12 E I_{0}
\end{gathered}
$$

and $M_{1}$ and $M_{2}$ are the restraining moments introduced by the outrigger action; $E I_{t}, E I_{0}$ and $E I_{c}$ are the bending stiffness of the core, the effective bending stiffness of outriggers and axial stiffness of columns; $H$ is the height of the core; $x_{1}$ and $x_{2}$ are the distances from the top to the outrigger levels; $w$ is the uniform horizontal loading as shown in Fig. 1.
The characteristic non-dimensional parameter $\omega$, which is a function of core-column stiffness ratio and core-outrigger stiffness ratio, is given by the following expression [2]:

$$
\omega=S_{v} / S_{h} H
$$

Eqs. (1) and (2) can be expressed in the matrix form, as well as the expression for the restraining moments introduced by the outriggers [3]:

$$
\begin{gathered}
S_{h} H\left[\begin{array}{cc}
\omega+\left(1-\xi_{1}\right) & 1-\xi_{2} \\
1-\xi_{2} & \omega+\left(1-\xi_{2}\right)
\end{array}\right]^{-1}\left\{\begin{array}{l}
M_{1} \\
M_{2}
\end{array}\right\}= \\
w H^{3} / 6 E I_{t}\left\{\begin{array}{l}
1-\xi_{1}{ }^{3} \\
1-\xi_{2}{ }^{3}
\end{array}\right\} \\
\left\{\begin{array}{l}
M_{1} \\
M_{2}
\end{array}\right\}= \\
\frac{w H^{2}}{6 E I_{t} s_{h h}}\left\{\begin{array}{l}
1-\xi_{1}{ }^{3} \\
1-\xi_{2}{ }^{3}
\end{array}\right\} \cdot\left[\begin{array}{cc}
\omega+\left(1-\xi_{1}\right) & 1-\xi_{2} \\
1-\xi_{2} & \omega+\left(1-\xi_{2}\right)
\end{array}\right]^{-1}
\end{gathered}
$$

For a structure with $n$ outriggers, Eq. (7) can be generalized in the following form [3]:

$$
\left\{\begin{array}{c}
M_{r 1} \\
M_{r 2} \\
M_{r n}
\end{array}\right\}=\frac{w H^{2}}{6 E I_{t} S_{v}}[A]\{B\}^{T}
$$

The top drift and base core moment in a multi-level outrigger structure are also expressed in a matrix form [3]:

$$
\begin{gathered}
\Delta_{0}=\frac{w H^{4}}{8 E I_{t}}-\frac{w H^{4}}{12 E I_{t}} \frac{1}{E I_{t} S_{h}}\{B\}[A]^{T}\{C\}^{T}=\frac{w H^{4}}{8 E I_{t}}-\Delta_{e} \\
M_{x}=\frac{w H^{2}}{2}-\frac{w H^{2}}{6 E I_{t} S_{h h}}\{B\}[A]^{T}\{e\}^{T}
\end{gathered}
$$

where, $\xi_{1}=\mathrm{x}_{1} / \mathrm{H}, \xi_{2}=\mathrm{x}_{2} / \mathrm{H}, \ldots, \xi_{n}=\mathrm{x}_{n} / \mathrm{H}$ and

$$
[A]=\left[\begin{array}{cccc}
\omega+\left(1-\xi_{1}\right) & 1-\xi_{2} & \ldots & 1-\xi_{n} \\
1-\xi_{2} & \omega+\left(1-\xi_{2}\right) & \ldots & 1-\xi_{n} \\
1-\xi_{n} & 1-\xi_{n} & \ldots & \omega \\
\{B\}=\left\{1-\xi_{1}{ }^{1} 1-\xi_{2}{ }^{3}\right. & \ldots & \left.1-\xi_{n}{ }^{3}\right\} \\
\{C\}=\left\{1-\xi_{1}{ }^{2} 1-\xi_{2}{ }^{2}\right. & \ldots & \left.1-\xi_{n}{ }^{2}\right\} \\
\{e\}=\left\{\begin{array}{llll}
1 & 1 & \ldots & 1
\end{array}\right\}
\end{array}\right.
$$

\section{Constrained Optimization Problem}

As mentioned by $\mathrm{Wu}$ and $\mathrm{Li}[3,6]$, outrigger floors represent irregularities in the stiffness distribution of a tall building, and they cause the formation of weak storeys near the outrigger levels under wind or earthquake action. Zhang et al. [7] studied a 50 storeys 

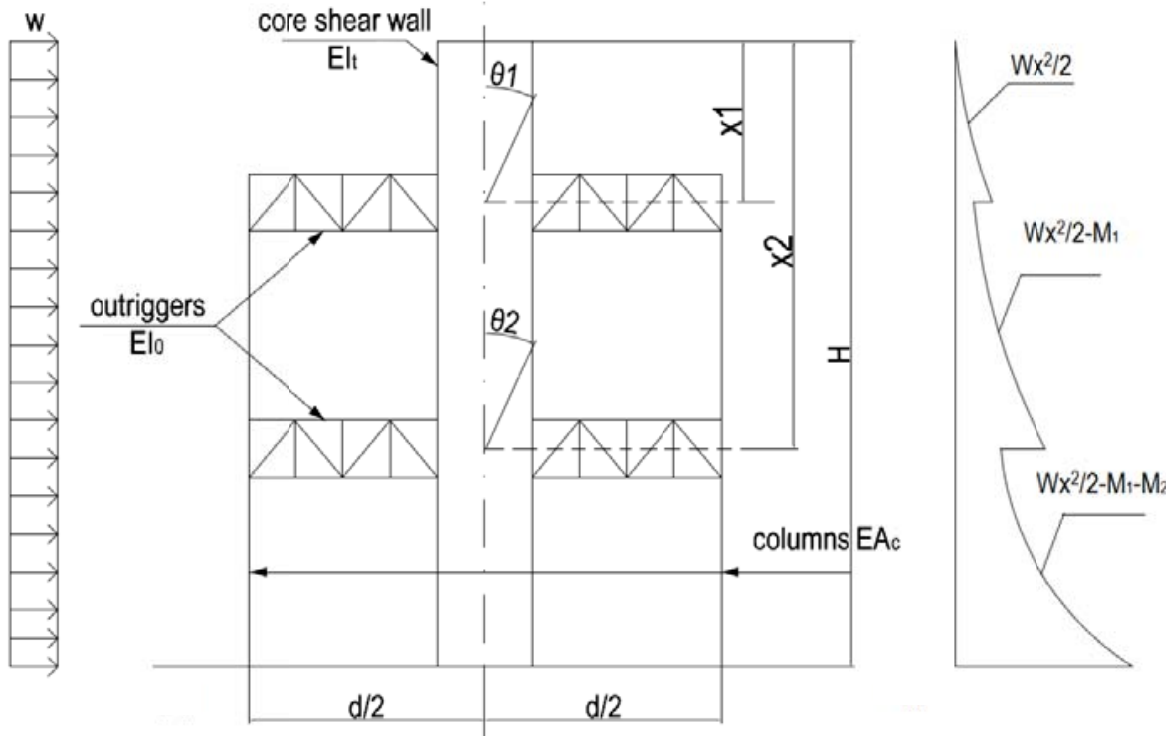

(a)

(b)

Fig. 1 (a) Configuration of structure with two outriggers; (b) bending moment diagram.

reinforced concrete tall building with central core, perimeter frames and one outrigger. Five cases with different outrigger floor rigidities (including the infinite rigid outrigger) were analyzed and it was concluded that for a better seismic design, outriggers should have lower rigidities and higher location than the optimum one.

This study will try to solve an optimum design problem predefined by $\mathrm{Wu}$ and $\mathrm{Li} \mathrm{[3]} \mathrm{and} \mathrm{namely} \mathrm{to} \mathrm{try}$ to reduce the core base moment for an outrigger-braced structure until the top drift will be under a specified limit. This constraint optimization problem with multiple variables can be solved by numerous methods: penalty function method, Lagrange multiplier, augmented Lagrange multiplier for inequality constraints, quadratic programming and gradient projection method. These classic methods are widely used, but new modern optimization methods are being used increasingly in fields where optimization is necessary. This paper will try to use one of these modern optimization techniques, namely the GA (genetic algorithm).

Genetic algorithms are based on the Evolutionary Theory of Darwin, namely the principle of "Survival of the Fittest". This optimization method takes into consideration the natural selection. The algorithm starts with the creation of the initial population and a representative value is calculated for each individual. With the help of a selection function based on certain criteria, some individuals are isolated so that a new generation is created. Two functions are used to obtain this new generations: mutation function and crossover function $[8,9]$.

The program used in this paper determines the optimum location of outriggers using genetic algorithms. The program is written using Matlab Optimization Toolbox. The mathematical formulation to the problem is described later in this chapter. The type of input to the fitness function is double vector, the default parameter of the ga-optimization algorithm.

The first step in the algorithm is creating an initial population using the "feasible population" function (@gacreationlinearfeasible) defined in Matlab language. This function gives random values to each individual, but with respect to the constraints defined but the user, which in this case are linear constraints [10]. In order to create a new generation, this ga-optimization method uses a function that selects a number of individuals called parents, and uses the mutation and crossover function. 
In every generation, the value of each individual is calculated using the fitness function and the stopping criteria of the program are verified.

Genetic algorithm creates three types of individuals for every generation: elite, crossover and mutation individuals. The first type consists of individuals with the best fitness value from the preceding generation and kept for the new generation. The number of individuals which "survive" is chosen by the user and in this case is two. Next, the algorithm creates crossover individuals by changing certain variables between two parents previously selected. The mutated individuals are created by selecting a number of variables from the actual individual and replacing them with random values. The genetic algorithm options mentioned above are given in Table 1.

In order to obtain a more accurate solution, a function which repeats the genetic algorithm was included. The

Table 1 Genetic algorithm options.

\begin{tabular}{ll}
\hline Population type & Double vector \\
\hline Selection Fcn & @selectiontournament \\
Initial population & Initialpopulation_Data \\
Population size & 100 \\
Generations & 100 \\
Elit count & 2 \\
Crossover fraction & 0.8 \\
\hline
\end{tabular}

stopping criteria are matching results for the certain number of times. For every execution, the individual from the solution of the last run is inserted in the initial population.

A basic flow-chart is given in Fig. 2, in order to get an idea of how the program works.

The form in which the problem is formulated is given below:

Purpose: minimize the moment at the core base $M_{x}$ which can be done by maximizing the value of the reduction efficiency for the base moment in the core defined as $[2,3]$ :

$$
\begin{gathered}
\rho M_{x}=\frac{\text { reduction of core base moment }}{\text { maximum possible reduction }} \\
\text { (core and columns behave fully composite) } \\
\rho M_{x}=\frac{1}{3}\{B\}[A]^{T}\{e\}^{T}
\end{gathered}
$$

Fitness function: $y=-1 / 3\{B\}[A]^{T}\{e\}^{T}$

Constraints:

(1) The value of top deflection should be less than an acceptable limit, in this paper, the limit for top deflection was chosen as:

$$
\begin{aligned}
& \Delta_{0} \leq \Delta_{\text {limit }} \\
& \Delta_{\text {limit }}=H / 400
\end{aligned}
$$

(2) Highest location of the first outrigger is set at the top of the building:

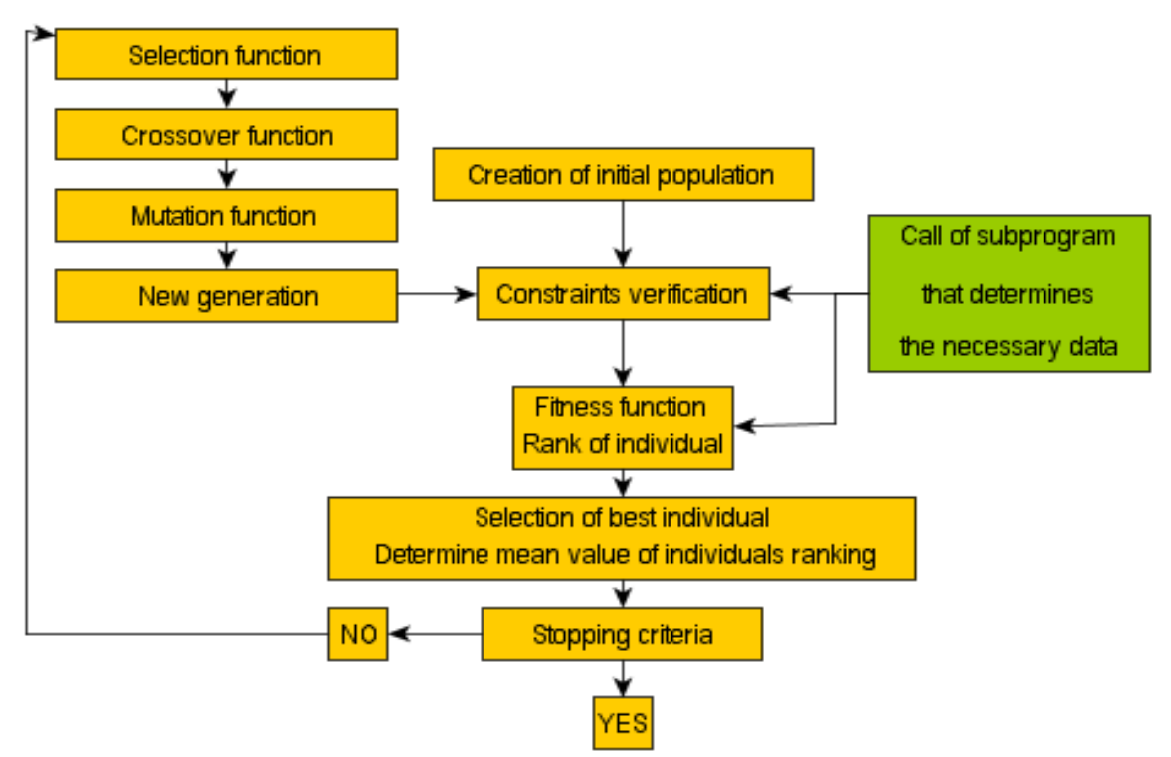

Fig. 2 Flow-chart for the program used in this paper. 


$$
\xi_{1} \geq 0
$$

(3) Lowest location of the last outrigger is set at the third floor from the base; this is conditioned due to the need for spacious ground lobbies that are common for tall buildings:

$$
\xi_{n} \leq(3 \times \text { storey height }) / H
$$

(4) The distance between two adjacent outrigger levels should be at least the height of 10 storeys, it is common in tall buildings to have mechanical floors at every 10 tenant floors, where the outriggers levels can be placed:

$$
\xi_{n} \geq \xi_{n-1}+(10 \times \text { storey height }) / H
$$

\section{Case Study}

A hypothetical outrigger-braced structure was considered in this paper, with reinforced concrete central core and braced outriggers that connect the core with the exterior columns. The analysis will be made for a plane frame with the configuration from Fig. 3 . The composite structure has the following properties:

\section{Concrete core:}

Elastic modulus: $E=3 \times 10^{7} \mathrm{kPa}$;

Wall width: $l=12 \mathrm{~m}$;

Wall thickness: $b=0.4 \mathrm{~m}$;

Wall bending stiffness: $E I_{t}=1.728 \times 10^{9} \mathrm{kNm}^{2}$.

Outrigger:

Elastic modulus: $E=2.1 \times 10^{8} \mathrm{kPa}$;

Bracing elements area: $A_{0}=0.01108 \mathrm{~m}^{2}$;

Outrigger bending stiffness: $E I_{0}=1.488 \times 10^{8} \mathrm{kNm}^{2}$;

Outrigger racking shear stiffness: $G A_{0}=4.537 \times 10^{6}$ $\mathrm{kNm}^{2}$.

External columns:

Elastic modulus: $E=2.1 \times 10^{8} \mathrm{kPa}$;

Cross section area: $A c=0.065 \mathrm{~m}^{2}$;

Column axial stiffness: $E I c=8.87 \times 10^{9} \mathrm{kNm}^{2}$;

Storey height: $4.0 \mathrm{~m}$;

Outrigger height: $8.0 \mathrm{~m}$.

In this study, the racking shear stiffness of the outrigger was accounted for. In his paper, Hoenderkamp and Bakker [4] had established two parameters, $S_{h}$ and $S_{v}$, which comprise the strains in the horizontal and vertical members, respectively. By applying a similar method, the racking shear stiffness of the outrigger was included in the analysis by using the following Eqs. (21) and (22), where, $\alpha=d / 2 b$, and $b$ represents the height of the outrigger.

$$
\begin{gathered}
S_{v}=1 / E I_{t}+1 / E I_{c} \\
S_{h}=b /\left(24 \alpha^{2} E I_{0}\right)+1 /\left(h \alpha^{2} G A_{0}\right)
\end{gathered}
$$

\subsection{Case Study No. 1}

Many studies regarding outrigger braced structure considered a maximum number of four outriggers. Smith and Coull [2] stated that buildings with more than four very stiff outriggers would have no significant gain in the efficiency reduction for top drift and core base moment than buildings with four outriggers. Many buildings that have been built with this structural system have indeed a number of outriggers limited to four. A new generation of high-rise buildings incorporate outriggers a number of levels greater than four: Taipei 101 has 11 sets of outrigger trusses over the height of the buildings, the Shanghai Tower has more than four outrigger trusses, the Jin Mao Tower has three sets of eight outrigger trusses.

Four cases were studied in this paper: optimum location of two, three, four and five outriggers for the same structure. Results are summarized in Table 2.

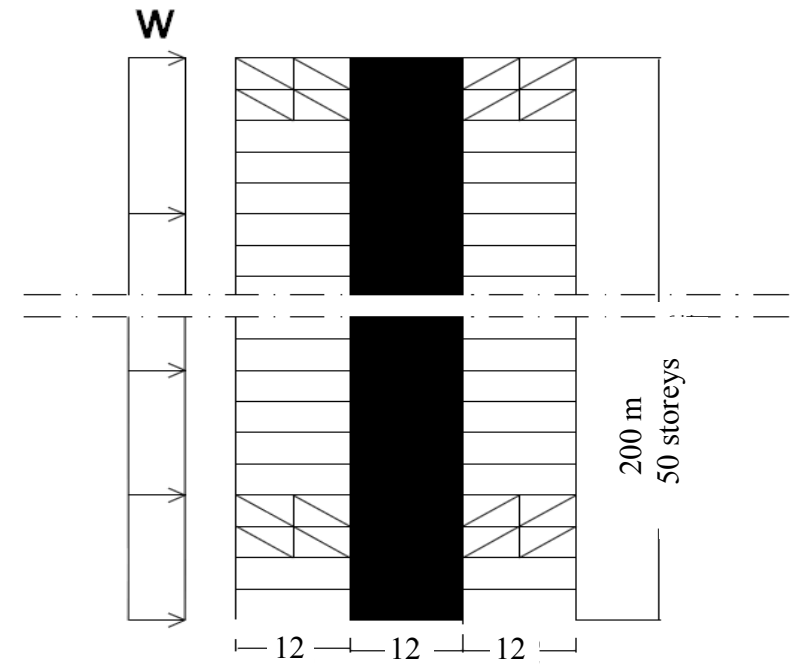

Fig. 3 Outrigger braced structure configuration. 
Table 2 Outrigger locations, core base moment and top drift for the example structure in all four cases.

\begin{tabular}{llll}
\hline Case $(\omega)$ & Outrigger positions $\xi=\left(\xi_{1} \xi_{2} \ldots \xi_{n}\right)$ & Base moment in core $(\mathrm{kNm})$ & Top drift $(\mathrm{m})$ \\
\hline Two outriggers $(0.1377)$ & $(0.5141,0.8300)$ & $1.0085 \mathrm{e}+005$ & 0.5 \\
Three outriggers $(0.1377)$ & $(0.5410,0.7410,0.9410)$ & $9.0754 \mathrm{e}+004$ & 0.4878 \\
Four outriggers $(0.1377)$ & $x=(0.3272,0.5272,0.7272,0.9272)$ & $8.7995 \mathrm{e}+004$ & 0.3710 \\
Five outriggers $(0.1377)$ & $x=(0.1398,0.3398,0.5398,0.7398,0.9398)$ & $8.7760 \mathrm{e}+004$ & 0.3427 \\
\hline
\end{tabular}

Table 3 Base moment and top drift in the structure for the four cases analyzed.

\begin{tabular}{|c|c|c|c|c|c|c|c|c|c|c|}
\hline & \multicolumn{2}{|c|}{ Four outriggers } & \multicolumn{2}{|c|}{ Five outriggers } & \multicolumn{3}{|c|}{ Six outriggers } & \multicolumn{3}{|c|}{ Seven outriggers } \\
\hline & $\omega=0.05$ & $\omega=0.122$ & $\omega=0.05$ & $\omega=0.122$ & $\omega=0.05$ & $\omega=0.122$ & $\omega=0.185$ & $\omega=0.05$ & $\omega=0.122$ & $\omega=0.185$ \\
\hline $\begin{array}{l}\text { Base moment } \\
(\mathrm{kNm})\end{array}$ & 87,398 & 122,450 & 86,798 & 108,730 & 86,750 & 108,590 & 117,250 & 86,753 & 103,550 & 115,830 \\
\hline Top drift (m) & 0.6 & 0.6 & 0.569 & 0.6 & 0.503 & 0.57 & 0.6 & 0.483 & 0.54 & 0.597 \\
\hline
\end{tabular}

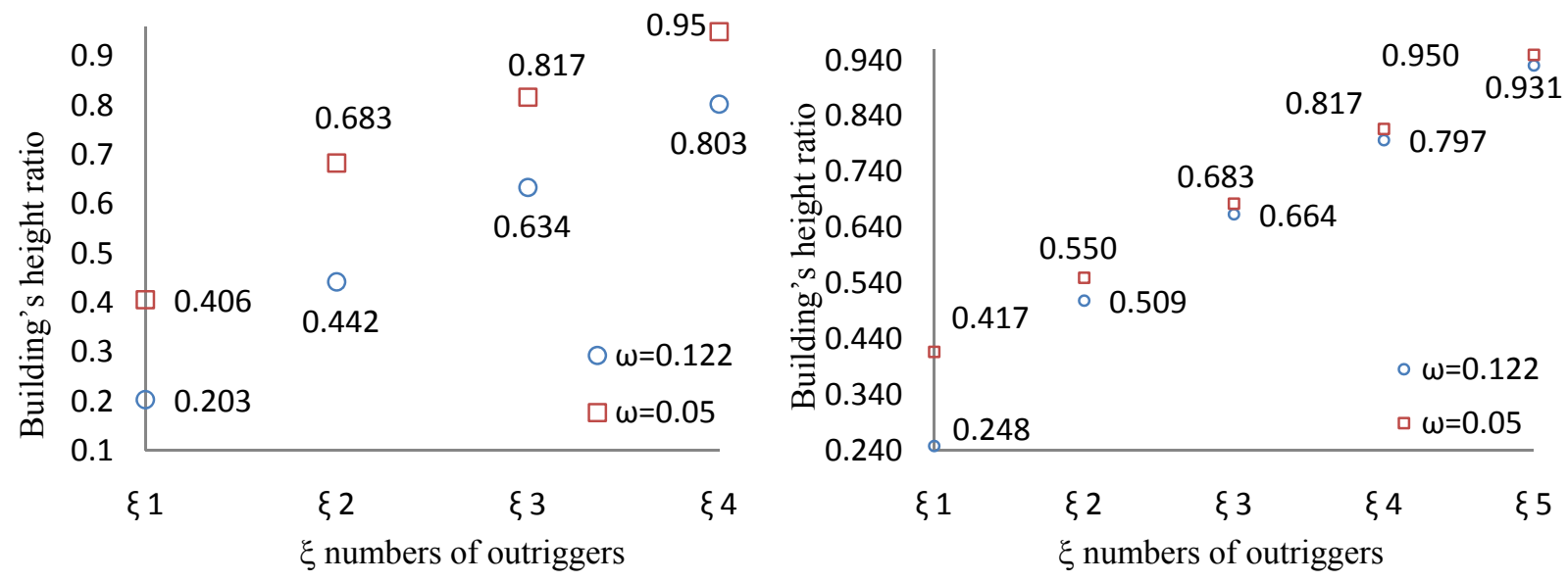

Fig. 4 Optimum location of four and five outriggers with different rigidities.
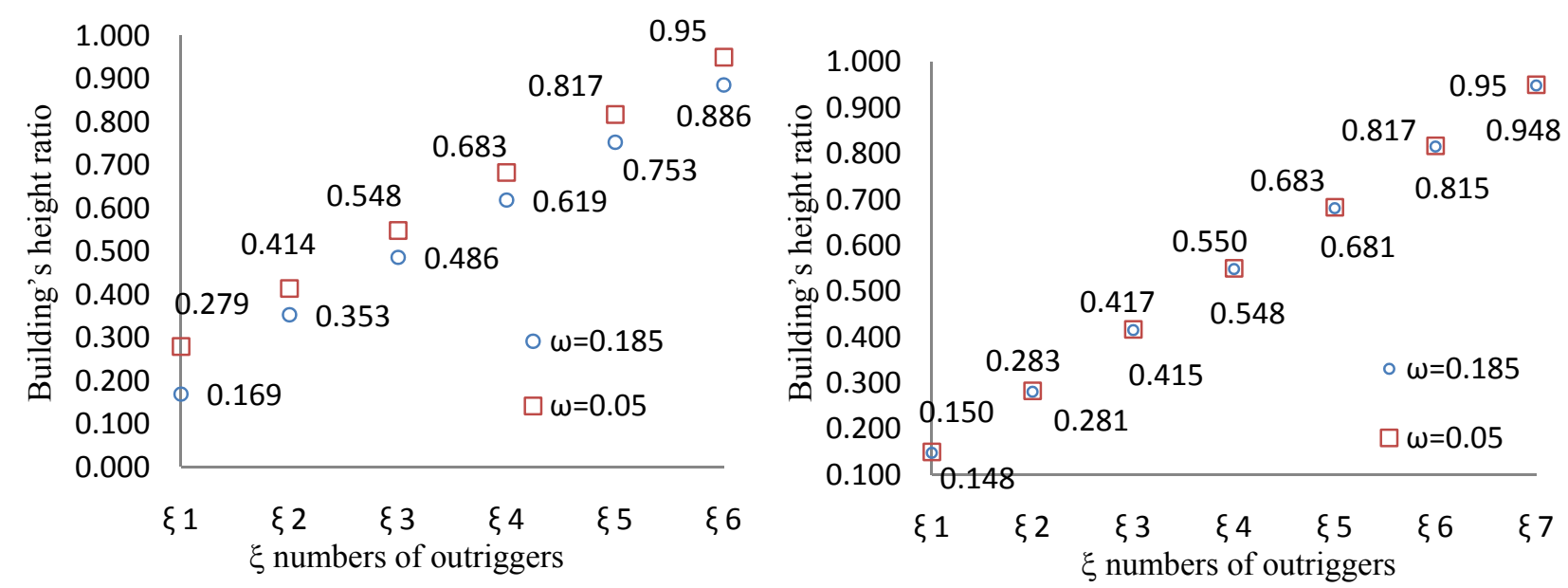

Fig. 5 Optimum distribution of six and seven outriggers with different rigidities.

\subsection{Case Study No. 2}

A similar building but with a height of $240 \mathrm{~m}$ and 60 floors will be analyzed by considering three different outrigger stiffness. This is achieved by varying the value of $\omega$ in those three cases. Only the outrigger rigidities are changed, while the bending stiffness and the column axial rigidity are taken as constants. The distance between two adjacent outrigger levels was 
reduced to eight floors. Results are presented in Figs. 4 and 5 , regarding the distribution of outriggers throughout the height of the building $\left(\xi_{i}\right)$ for the cases when the building has four, five, six and seven outriggers, respectively. Table 3 shows the results conserving the efficiency for each case: base moment and top drift. Results are analyzed in conclusion part of the article.

\section{Conclusions}

The following conclusions can be made from the above analyses:

- For the first example building, the reduction efficiency for core base moment is almost the same for five and four outriggers, from another point of view, the top drift is lower in the five outriggers braced building case;

- For the second example building, in all four cases (4-7 outriggers), the more rigid the outriggers, the higher the optimum location, for the case of seven outriggers the location of outriggers is dictated by the limit of eight floors between two adjacent outriggers. For the same building, if outriggers are made more rigid $(\omega=0.05)$, there is no significant reduction of core base moment for more than four outriggers, but the top drift is reduced by almost $20 \%$. In the case of $\omega$ $=0.122$ (outriggers are more flexible), the reduction of core base moment is more significant from four outriggers to seven outriggers integrated in the building and reduction of top drift is $10 \%$. This could be a good alternative to stiffer outrigger levels, which have the downside of forming weak floors near them. At the same time, in order to reduce the value of the structural parameter $\omega$ from 0.122 to 0.05 without changing the properties of the core and exterior columns, the rigidity of the outrigger has to be increased 10 times, in this case.

This is not necessary the best option to be considered due to the same irregularity in stiffness distribution along the height.

\section{References}

[1] B. Taranath, Wind and Earthquake Resistant Buildings Structural Analysis and Design, Marcel Dekker Publications, New York, 2005, pp. 283-298.

[2] B.S. Smith, A. Coull, Tall Buildings Structures: Analysis and Design, Wiley Interscience Publication, United States, 1991, pp. 355-371.

[3] J.R. Wu, Q.S. Li, Structural performance of multi-outrigger braced tall buildings, Journal of Structural Design of Tall and Special Buildings 12 (2) (2003) 155-176.

[4] J.C.D. Hoenderkamp, M.C.M. Bakker, Analysis of high-rise braced frames with outriggers, Journal of Structural Design of Tall and Special Buildings 12 (2003) 335-350.

[5] J. Lee, H. Kim, Simplified analytical model for outrigger-braced structures considering transverse shear deformation, in: Proceedings of the CTBUH Seoul Conference, Seoul, Oct. 2004, pp. 997-1002.

[6] Q.S. Li, J.R. Wu, Correlation of dynamic characteristics of a super-tall buildings from full-scale measurements and numerical analysis with various finite element models, Journal of Earthquake Engineering and Structural Dynamics 33 (2004) 1312-1336.

[7] J. Zhang, Z.X. Zhang, W.G. Zhao, H.P. Zhu, C. Zhou, Safety analysis of optimal outriggers location in high-rise building structures, Journal of Zhejiang University 18 (2) (2007) 264-269.

[8] S.N. Sivanandam, S.N. Deepa, Introduction to Genetic Algorithms, Springer Publication, Springer Berlin Heidelberg, New York, 2008.

[9] D.A. Coley, An Introduction to Genetic Algorithms for Scientist and Engineers, World Scientific Publishing, Singapore, 1999.

[10] Global Optimization Toolbox, User's Guide, Copyright 2004-2010 by the MathWorks, Inc., 2011. 